\title{
ESTRATÉGIAS NUTRICIONAIS PARA MANIPULAÇÃO DA CONCENTRAÇÃO DE COLESTEROL NO OVO DE POEDEIRAS COMERCIAIS
}

\author{
Adolpho Marlon Antoniol de MOURA ${ }^{1 *}$ \& Thiago Vasconcelos MELO ${ }^{2}$
}

1 Fundação Oswaldo Cruz. Instituto de Tecnologia em Imunobiológicos Bio-Manguinhos. Laboratório de Experimentação Animal. Rio de Janeiro, RJ, Brasil.

2 Universidade Federal dos Vales do Jequitinhonha e Mucuri. Instituto de Ciências Agrárias, Campus Unaí, Minas

Gerais, Brasil.

*Autor para correspondência: adolpho.moura@bio.fiocruz.br

\section{RESUMO}

Durante décadas o colesterol foi associado a doenças vasculares e cardiopatias, sendo por inúmeras vezes contraindicado o seu consumo, e consequentemente o ovo. Visando impulsionar o aumento no consumo per capita de ovos, inúmeras pesquisas foram conduzidas com o objetivo de reduzir a concentração de colesterol na gema do ovo de poedeiras comerciais, a partir de manipulações dietéticas de galinhas e codornas. Os resultados obtidos se mostraram eficientes em diversas estratégias tais como carvão vegetal, fontes de óleos, compostos fenólicos etc. Entretanto, mecanismos fisiológicos adaptativos impedem que as aves mantenham as concentrações de colesterol reduzidas permanentemente. Objetivou-se com esta revisão discutir resultados de protocolos científicos conduzidos para reduzir a concentração de colesterol na gema do ovo de poedeiras.

Palavras chave: Colesterol; Qualidade do ovo; Galinhas poedeiras; Carvão vegetal; Gema.

\begin{abstract}
For decades, cholesterol has been associated with vascular diseases and heart diseases, and its intake, and consequently the egg, has been contraindicated for many times. Aiming to boost the increase in per capita egg intake, researches were conducted with the objective of reducing the cholesterol concentration in the egg yolk of commercial laying hens, from dietary changes of chickens and quails. The results obtained were efficient in several strategies such as charcoal, sources of oils, phenolic compounds, etc. However, adaptive physiological mechanisms prevent birds from maintaining cholesterol concentrations permanently reduced. The objective of this review was to discuss the results of scientific protocols conducted to reduce the cholesterol concentration in the egg yolk of laying hens.
\end{abstract}

Keywords: Cholesterol; Egg quality; Laying hens; Vegetal charcoal; Yolk.

\section{Introdução}

O ovo é um alimento de elevado valor biológico, devido a sua inigualável composição bromatológica, onde estão balanceados nutrientes essenciais, com destaque para os aminoácidos, vitaminas lipossolúveis, lipídeos e minerais. Segundo Oba et al. (2005) a fração lipídica do ovo corresponde a $33 \%$ do peso da gema, sendo seus principais componentes os triglicerídeos, os fosfolipídeos, os ácidos graxos livres e o colesterol. Este último tem recebido atenção particular por parte da comunidade científica devido à sua importância na saúde coletiva por ser associado 
aos fatores de cardiopatias e aterosclerose. Por isso, durante anos o ovo foi considerado um alimento restritivo às pessoas com dislipidemias, e consequentemente isso teve impacto negativo sobre o consumo per capita do produto.

O perfil lipídico dos ovos é influenciado por fatores como: genética, idade, alimentação e tipo de gordura dietética (AUSTIC, 1994). Em consequência disso, inúmeras pesquisas foram desenvolvidas com o objetivo de alterar a composição do ovo, em particular na redução da concentração de colesterol na gema, a partir da manipulação dietética das aves. A estratégia se concentra na inclusão de aditivos ou nutrientes que interfiram na absorção ou biossíntese do colesterol sem que haja prejuízos na produção e qualidade dos ovos comerciais.

Dentre as pesquisas realizadas destaca-se a inclusão dietética das cinzas de carvão vegetal (FANCHIOTTI et al., 2010), minerais e probióticos (OBA et al., 2005), fontes de óleo (MURATA et al., 2003; COSTA et al., 2008), matérias primas da ração (KOVACS et al., 2000) e até fármacos (MORI et al., 2000). Entretanto os resultados são controversos devido à complexa interação entre os balanços de colesterol endógeno e dietético que são excretados pelo intestino, reciclados ou destinados à deposição na gema do ovo. Muito embora as principais referências sobre o tema datam décadas passadas elas são fundamentais para nortear futuros estudos que elucidem as lacunas do conhecimento ainda não fundamentadas pela ciência. A fim de compreender melhor os mecanismos de deposição do colesterol no ovo a partir de resultados experimentais foi elaborada esta revisão de literatura.

\section{Revisão de literatura}

\subsection{O colesterol}

O colesterol (3-hidróxi-5,6-colesteno) pertence à classe dos lipídios derivados, isto é, substâncias obtidas pela hidrólise de outros compostos lipídicos. O colesterol pertence ao grupo dos terpenóides, os quais são polímeros do isopreno e faz parte do grupo dos esteróides, nome genérico dados aos lipídios que contém o núcleo ciclopentanoperidrofenantreno (KLASING, 1998), como ilustrado na Figura 1.

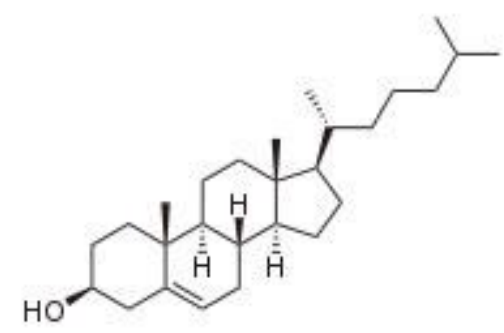

Figura 1: Molécula do colesterol.

Os esteróis são componentes não-glicerídeos presentes nos óleos vegetais e gorduras animais. São álcoois cristalinos com elevado ponto de fusão e estrutura complexa, sendo o colesterol o principal esterol de origem animal e os fitosteróis, esteróis do reino vegetal (MORETTO \& FETT, 1998). Segundo Maynard et al. (1984), o colesterol é um dos mais importantes esteróis do organismo animal, podendo ser encontrado nos tecidos, no sangue, na bile, nas gorduras, no ovo, na manteiga e na lanolina da lã, sendo suas principais funções:

○ Importante componente da membrana plasmática das células; 
- Influencia na permeabilidade e integridade celular;

- Participa na formação dos ácidos biliares;

○ Síntese de hormônios esteroides, adrenais e da vitamina $\mathrm{D}_{3}$.

Assim como no organismo dos mamíferos, a molécula de acetil-CoA é, no organismo das aves, a fonte doadora de átomos de carbono para a síntese do colesterol. Do mesmo modo, o processo de formação da molécula do colesterol envolve a síntese do lanosterol e a síntese do colesterol propriamente dito (GRIMINGER, 1986).

Nas aves as lipoproteínas, chamadas protomícrons (d<1,006), são absorvidas no sistema porta-hepático e enviadas diretamente à corrente sanguínea (SHAFEY, 2001). Nos mamíferos os quilomícrons $(\mathrm{d}<0,96)$ são transportados pelo sistema linfático intestinal. Porém, em ambos o principal sítio de síntese do colesterol ocorre no fígado. As lipoproteínas encontradas no plasma sanguíneo das aves domésticas são as de densidade muito baixa (VLDL e protomícrons), as de baixa densidade (LDL), as de alta densidade (HDL) e as de densidade muito alta (VHDL ou vitelogeninas - VTG). Segundo Nimpf e Schneider (1991), o colesterol plasmático é transportado via VLDL e depositado nos folículos em desenvolvimento por endocitose via receptor (apoproteína B) localizado na membrana plasmática dos ovócitos.

Aproximadamente metade do colesterol do corpo é obtido através da biossíntese de novo, chamado turnover. A biossíntese do colesterol ocorre no citoplasma e nos microssomos a partir do carbono " 2 " do grupo acetato da acetil-CoA. O processo tem seis passos principais:

1. As acetil-CoA's são convertidas para 3-hidroxi-3-metilglutaril-CoA (HMG-CoA);

2. A HMG-CoA é covertida a mevalonato;

3. O mevalonato é convertido para a molécula base de isopreno chamada, Pirofosfato de Isopentenil (IPP), com a concomitante perda de $\mathrm{CO}_{2}$;

4. IPP é convertido a esqualeno;

5. Esqualeno é convertido a lanosterol;

6. Lanostetol é convertido a colesterol.

$\mathrm{Na}$ avicultura de postura, as aves são alimentadas com rações isentas de colesterol, dessa forma, a maior quantidade do colesterol do ovo, e dos tecidos, têm origem endógena. Porém, quando há adição de colesterol à ração, a sua biossíntese hepática é reduzida e, com isso, aumenta a excreção fecal do colesterol, sem alterar a síntese ovariana. Segundo Bitman \& Wood (1980), a taxa de deposição de colesterol na gema reduz com o aumento na produção e no tamanho do ovo. Embora o colesterol presente na gema do ovo seja sintetizado no fígado e transportado via corrente sanguínea na forma de lipoproteínas, a concentração do colesterol plasmático não está estritamente associada com a concentração de colesterol da gema. Além disso, estudos in vitro demonstraram que as membranas ao redor do ovário sintetizam colesterol a partir do acetato (SUTTON et al., 1984).

O colesterol é prontamente transferido do sangue através das membranas ovarianas para o desenvolvimento do oócito e que maior parte, senão todo, o colesterol da gema do ovo é oriundo do sangue. Testes in vitro demonstram que a biossíntese de lipídios nos tecidos ovarianos contrasta marcadamente com a que ocorre no fígado. A origem da maioria dos lipídios encontrados na gema ovo, incluindo o colesterol é o fígado (NABER, 1983).

A produção de ovos requer a deposição de grande quantidade de lipídios na gema, principalmente no início da ovulação. Os lipídios da gema são sintetizados no fígado e sob influência do estrogênio e progesterona são transferidos do sangue para os folículos ovarianos. 
Esses lipídios da gema podem ser de dois tipos: lipoproteínas e vitelogeninas. Na galinha, as lipoproteínas contribuem aproximadamente com 95\% dos lipídios da gema. O fígado sintetiza e secreta triacilglicerol e fosfolipídios, em especial a lipoproteína VLDL (lipoproteína de densidade muito baixa) que apresenta características bioquímicas e estrutura única para atuar no ovário (WALZEN, 1996).

Essa lipoproteína tem a metade do tamanho normal da molécula VLDL e possui a apoproteína VLDL II em sua superfície, tornando-se um substrato ruim para a lipase lipoprotéica. Consequentemente, os triacilgliceróis ligados a VLDL não são bem utilizados pelo músculo esquelético ou tecido adiposo. Esse tamanho reduzido permite a passagem através da lâmina granulosa basal do folículo ovariano e liga-se ao receptor da apolipoproteína-B na oolemma. O processo de incorporação dos lipídios do sangue para a gema ocorre por endocitose (KLASING, 1998).

A ação seletiva da lâmina basal do folículo ovariano previne o aumento dos protomícrons que chegam através da dieta. Essa combinação entre a ultraestrutura folicular e tamanho da VLDL II, permite que a gordura dietética seja modificada no fígado e, prioritariamente, incluída na gema, permitindo melhor controle das características dos lipídios da gema pela fêmea. Essa modificação hepática não é completa, e a composição dos lipídios da gema são reflexos da dieta, especialmente no conteúdo de PUFA's (NOBLE et al., 1996). A Figura 2 ilustra resumidamente o metabolismo do colesterol na ave e a deposição na gema do ovo.

A vitelogenina é uma proteína sintetizada pelo fígado da poedeira que se complexa com os fosfolipídios e colesterol. Essa lipoproteína é aumentada para o desenvolvimento do oócito e sua clivagem fornece fosfovitina e lipovitelina. A intensa síntese de lipoproteínas pelo fígado ocorre rapidamente, sendo essa mobilização dos hepatócitos, resultando em um temporário aumento do tamanho do fígado e da quantidade de lipídios fazendo com que a cor da gema seja alterada para o amarelo (JACKSON et al., 1977)

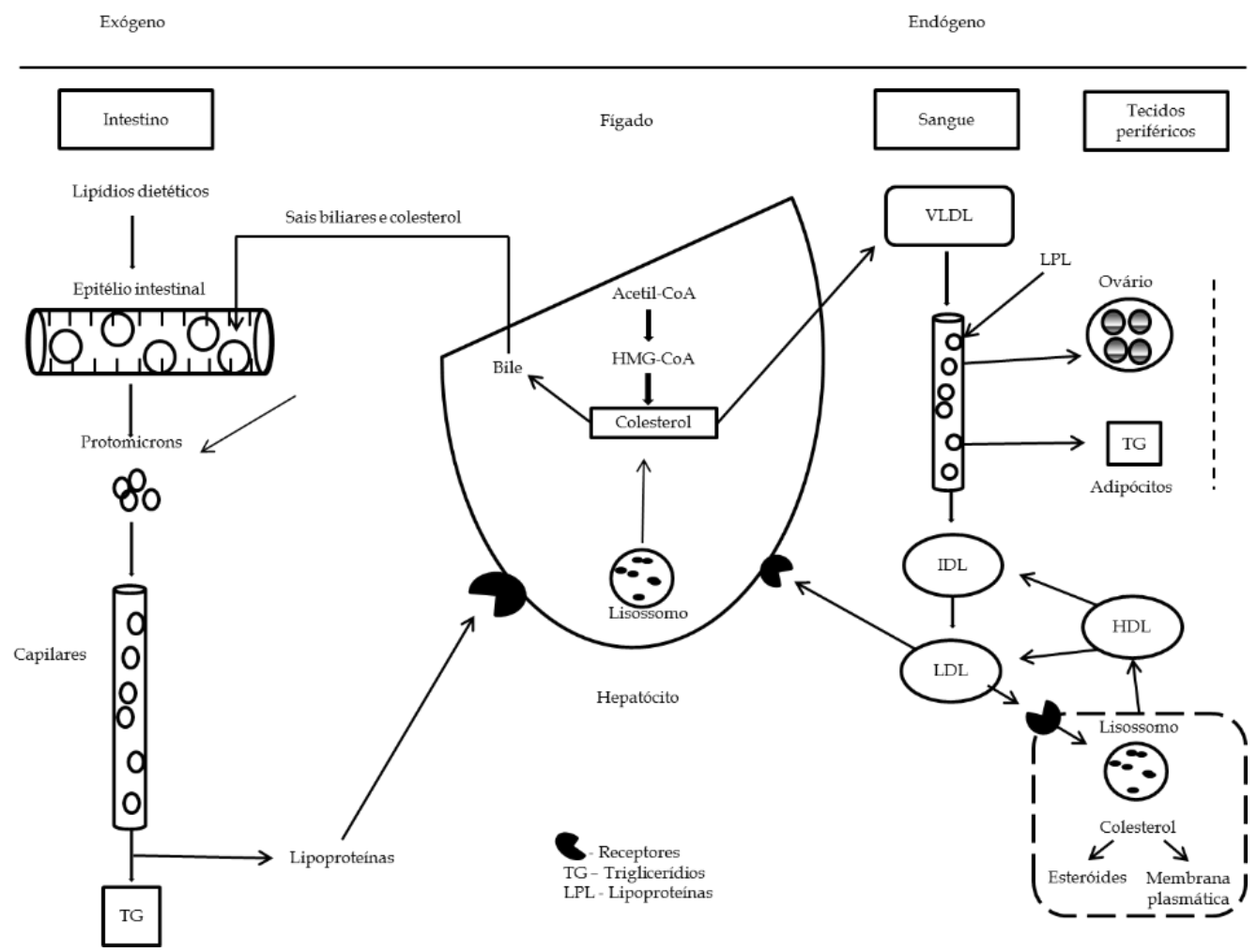

Figura 2: Metabolismo e deposição do colesterol no ovo da ave (Adaptado de KLASING, 1998). 


\section{ACTA

\subsection{Estratégias empregadas na redução do colesterol do ovo}

A busca por melhor qualidade de vida tem levado a população modificar seus hábitos, dentre eles uma alimentação mais equilibrada e saudável. Isso tem exigido do mercado modificações no perfil nutricional dos alimentos, como por exemplo, a redução do teor de gordura saturada e do colesterol dos produtos de origem animal. Em convergência a essa realidade, estudos tem sido conduzidos principal mente através da manipulação das dietas dos animais, para atender as exigências do mercado consumidor.

Durante muitos anos o ovo foi estigmatizado como potencializador de agravos a saúde, principalmente as cardiopatias devido ao seu elevado teor de colesterol na gema. Entretanto esse sofisma foi desconstruído ao longo dos anos a partir dos resultados de pesquisas nos diferentes âmbitos científicos, em que, na verdade o consumo do ovo deve ser incentivado em função da sua incomparável qualidade nutricional. Como qualquer outra fonte lipídica o ovo deve ter seu consumo restringido apenas aos grupos de pessoas que sejam portadoras de disfunções ou patologias metabólicas, como por exemplo, a hipercolesterolomia.

A composição bromatológica do ovo é influenciada diretamente pela dieta da ave, porém, a manipulação na concentração de colesterol ainda controversa (COSTA et al., 2008). Por se tratar de um gameta apto a fecundação, o ovo dispõe de mecanismos fisiológicos que garantem o equilíbrio entre os seus componentes para que o desenvolvimento embrionário não seja comprometido.

Sob o prisma zootécnico, a produção de ovos com baixa concentração de colesterol, contemplará um mercado com amplo potencial a ser explorado, além de agregar valor comercial ao produto. Desta maneira, estudos de viabilidade econômica devem ser precedidos a fim de garantir a sustentabilidade da cadeia produtiva em virtude de uma possível redução na produtividade de ovos.

Estudos conduzidos para verificar o efeito do perfil lipídico dietético sobre a concentração de colesterol na gema remetem aos anos de 1950 quando Fisher \& Leveille (1957) concluíram que a gordura dietética parece não ter efeito sobre a deposição de colesterol na gema do ovo. Posteriormente, Hargis et al. (1991) avaliaram o efeito de uma dieta contendo 3\% de óleo de pescado e outra sem adição de gordura e verificaram redução significativa do colesterol na gema do ovo das poedeiras que consumiram a ração contendo óleo de peixe.

O colesterol dietético exerce efeito marcante, em torno de $25 \%$, sobre o conteúdo de colesterol na gema do ovo. A inclusão de colesterol na ração provoca aumento significativo nos teores de colesterol na gema e nas excretas, e diminuição na biossíntese do colesterol endógeno a partir do acetato. $\mathrm{O}$ aumento da excreção do colesterol via ovo é um mecanismo fisiológico que mantém a normocolesterolemia durante a ingestão de rações com altos níveis de colesterol (SIM et al., 1980).

A quantidade e o tipo de ácidos graxos presentes na dieta têm efeito marcante sobre o metabolismo dos esteróis nas aves. A absorção do colesterol dietético pelas aves pode estar relacionada, com a composição química do óleo ou gordura fornecidos na dieta. Adicionando $20 \%$ de óleo de soja, óleo de coco ou óleo de girassol nas dietas para poedeiras, Bartov et al. (1971) concluíram que a dieta contendo óleo de soja provocou menor concentração de colesterol na gema. Do mesmo modo, Hirata et al. (1986) relataram que, embora o perfil de ácidos graxos da gema seja marcadamente influenciado pelo fornecimento de rações contendo diferentes fontes lipídicas (óleo de soja, óleo de coco, banha ou sebo), o teor de colesterol não sofreu alteração significativa.

Hodzic et al. (2005), estudando a possibilidade de modificar o nível de colesterol total da gema de ovos por meio da suplementação com diferentes gorduras (3\% de óleo de peixe, 3\% de 


\section{ACTA

óleo de palma e 3\% de banha de porco), observaram que o colesterol total da gema é constante e pode ser influenciado somente em algumas condições, por exemplo, quando as poedeiras foram alimentadas com 3\% de banha de porco.

Estudos conduzidos por Vilchez et al. (1991) indicam que outras aves domésticas apresentam mecanismos metabólicos semelhantes. Eles não observaram diferenças significativas no teor de colesterol da gema, utilizando, nas rações para codornas japonesas, 3\% dos ácidos palmítico (saturado), oléico (monoinsaturado) e linoléico (poliinsaturado). Shafey (1998) adicionou 20\% de óleo de girassol na dieta para poedeiras e não observou aumento significativo no teor de colesterol da gema.

Conforme já discutido, o fornecimento de alimentos ricos em ácidos graxos $\omega$-3 ( $\alpha$ linolênico, eicosapentaenóico-EPA e docosahexaenóico-DHA) nas dietas para poedeiras, provoca modificações no perfil de ácidos graxos da gema, tornando o ovo uma excelente fonte desses ácidos graxos (BAUCELLS et al., 2000). Porém, inúmeras pesquisas corroboram na assertiva de que não há redução significativa na concentração de colesterol na gema, independente da fonte lipídica fornecida às aves (MENDONÇA JR. et al., 2000; MURATA et al., 2003; COSTA et al., 2008).

Os ácidos graxos ômega-3 e ômega-6 apresentam efeitos hipocolesterolêmicos e reduzem os níveis de lipoproteínas de baixa densidade (LDL), pois modificam a composição das membranas celulares e das lipoproteínas e induzem o aumento das excreções biliar e fecal do colesterol, reduzindo a síntese das lipoproteínas de muito baixa densidade (VLDL) no fígado, o que poderia ocasionar redução do teor de colesterol no ovo (HARGIS \& VAN ELSWYK, 1993). Considerando que apenas $21 \%$ do colesterol da gema encontram-se sob a forma esterificada, reduções substanciais no colesterol somente seriam alcançadas mediante a modificação na composição das lipoproteínas sintetizadas no fígado, que entram na formação da gema.

\subsection{Fibra vegetal}

Diversas pesquisas têm sido conduzidas com a fibra dietética no sentido de diminuir o colesterol do ovo, entretanto os resultados ao longo dos anos indicam não ser possível asseverar os reais efeitos das fontes de fibras sobre a redução na concentração de colesterol na gema. A fibra exerce influência sobre o metabolismo do colesterol pela possível combinação com os sais biliares com diminuição da absorção do colesterol e pela redução no tempo de permanência da digesta no trato gastrintestinal, aumentando a excreção do colesterol (VARGAS e NABER, 1984).

Os efeitos da inclusão de cinco diferentes fontes de fibra na dieta para codornas japonesas foram avaliados por Sutton et al. (1981). Foram incluídos de celulose pura e 6,25\% de pectina pura. De acordo com os resultados obtidos, as dietas não provocaram efeito significativo sobre o teor de colesterol na gema. Beyer e Jensen (1993) não observaram alteração significativa no teor de colesterol da gema após a adição de $20 \%$ de farinha de cevada na dieta para poedeiras. Alimentando poedeiras com uma dieta contendo $6,2 \%$ de fibra $(37,70 \%$ de trigo $+37,70 \%$ de grãos inteiros de arroz), Shafey et al. (1998) observaram queda significativa no teor de colesterol da gema.

Notoriamente o consumo de ração está diretamente correlacionado com o balanço energético da ave, e desta maneira pesquisas foram conduzidas com o objetivo de determinar a relação entre o consumo, ganho de peso vivo e concentração de colesterol na gema. Segundo Vargas e Naber (1984) redução na ingestão diária de energia não surtiu efeito sobre a concentração de colesterol na gema.

\subsection{Fitosteróis}


O efeito dos esteróis das plantas como redutores do colesterol nas aves tem sido amplamente estudado. Os esteróis das plantas, também chamados fitosteróis são compostos semelhantes ao colesterol e incluem mais de 250 compostos diferentes, encontrados nas plantas e nos organismos aquáticos (WESTER, 2000; PIIRONEN et al., 2000). Os representantes mais comuns dos fitosteróis são: o sitosterol, stigmasterol, campesterol e o avenasterol. As principais fontes de fitosteróis são os óleos vegetais, seguidos dos cereais, castanhas e nozes. Os fitosteróis são formados de modo semelhante ao colesterol nos animais, a partir do acetil-CoA, mevalonato e metilação do esqualeno.

Segundo Wester (2000), o mecanismo de ação dos fitosteróis sobre a redução do colesterol ainda não está totalmente elucidado. De acordo com Moghadasian (2000), estudos in vitro e com animais sugerem que os fitosteróis têm alta afinidade pelas micelas nas quais o colesterol encontrase agregado. Dessa forma, os esteróis das plantas substituíram o colesterol nas micelas, diminuindo a absorção do colesterol. Além disso, os fitosteróis podem inibir a atividade de algumas enzimas envolvidas no metabolismo do colesterol, tais como a acetil-CoA carboxilase e a HMG-CoA redutase.

Clarenburg et al. (1971) adicionaram às dietas para poedeiras níveis crescentes de $\beta$-sitosterol e observaram reduções acima de $35 \%$ no teor de colesterol da gema. Ao contrário, Kudchodkar et al. (1976) não observaram resposta significativa para o teor de colesterol na gema ao adiciona às dietas de poedeiras $4 \%$ de uma mistura de fitosteróis (65\% de sitosterol; $30 \%$ de campesterol e 5\% de stigamasterol).

Sim e Bragg (1977) adicionaram 2\% de esteróis de sojas às dietas para poedeiras contendo diferentes tipos de gorduras (saturadas e insaturadas), com ou sem adição de colesterol dietético. Segundo esses autores, os teores de colesterol no plasma e na gema sofreram redução na faixa de 16 a 33\% dependendo do tipo de lipídio utilizado nas dietas.

\subsection{Metabólitos secundários}

Determinados grupos de substâncias produzidas pelos vegetais, possuem eficácia comprovada na redução do colesterol, tanto nos animais como no homem. Essas substâncias são chamadas de "metabólitos secundários". Os principais metabólitos secundários com atividade hipocolesterolêmica são: carotenóides, flavonóides licopeno e saponinas (OLIVEIRA et al., 1999; LIMA et al., 2001 e OLIVEIRA et al., 2008).

Os metabólitos secundários das plantas, conhecidos como "produtos secundários" ou "produtos naturais", podem ser divididos em três grupos quimicamente distintos: terpenos, compostos fenólicos e compostos nitrogenados, mas este último grupo não será discutido neste trabalho. Metabólitos secundários diferem dos primários, por terem distribuição restrita no reino vegetal, ou seja, são encontrados somente em algumas espécies vegetais. Terpenos são lipídios sintetizados a partir do acetil-CoA ou a partir de intermediários básicos da glicólise. Compostos fenólicos são substâncias aromáticas formadas por vias especiais, onde aminoácidos aromáticos são formados a partir de carboidratos precursores derivados da via do ácido chiquímico ou pela via do ácido malônico (TAIZ \& ZEIGER, 1998).

Os flavonóides constituem o maior de substâncias fenólicas naturais que possuem atividades biológicas bastante diversificadas, como antioxidantes, antiflamatórios, anticarcinogênicos, dentre outras. São classificados primariamente em seis em grupos diferentes, pelo grau de oxidação da cadeia de três carbonos. São eles: as antocianinas, as flavononas (naringina), as flavonas (apigenina e luteolina), os flavonóis (quercetina), as isofloavonóides (biochanina A) e as catequinas. Este último grupo apresenta atividade de esteróide. São constituídos por dois anéis aromáticos (C6) 
conectados por uma ponte, formada por três átomos de carbono que são biossintetizados a partir da fenilalanina na via do ácido chímico ou do acetil-CoA, via rota do ácido malônico (LIMA et al., 2001).

O mecanismo de absorção e metabolismo dos flavonóides ainda não foi elucidado, porém sabe-se que são conjugados no fígado e rins, com posterior excreção através da bile e urina. Os flavonóides extraídos da berinjela podem reduzir a atividade da enzima HMG-CoA redutase e aumentar a taxa de degradação do colesterol pelo aumento na concentração de esteróides neutros no fígado (PETERSON \& DWYER, 1998).

Diversos estudos foram conduzidos para se verificar os efeitos dos flavonóides em dietas hiperlipidêmicas. A apigenina, um importante flavonóide, atua inibindo a enzima aldose redutase, que por sua vez converte açúcar em álcoois e cuja atividade pode estar associada à formação de catarata em indivíduos diabéticos. Também há a hipótese de que a catequina possua efeito hipocolesterolêmico por elevar a excreção de bile (MURAMATSU et al., 1986).

São substâncias fenólicas (triterpenóides) glicosídios de antocianidinas, polihidroxi derivadas do cátion flavilium. Apresentam-se sob a forma de diferentes estruturas em equilíbrio, com predominância do cátion flavilium (vermelho) somente em condições ácidas (Sarni-Manchado et al., 1996). Pertencem à família dos flavonóides e constituem grupo de pigmentos solúveis em água responsável pela maioria das cores vermelha, laranja e azul de flores, frutas e vegetais. As antocianinas são glicosídeos, pois, possuem um açúcar na posição 3, e as vezes, em outro local, porém sem esses açúcares, são classificadas como antocianidinas.

O resveratrol é uma antocianina capaz de inibir a enzima HMG-CoA redutase e consequentemente, a síntese de colesterol. Outra importante função das antocianinas é a de antioxidante, que parece ser bem mais eficiente que o $\alpha$-tocoferol na prevenção da peroxidação dos lipídios e na remoção dos radicais livres (DELGADO-VARGAS et al., 2000; IGARASHI et al., 2000). Apesar do efeito hipocolesterolêmico das antocianinas nos animais e no homem terem sido comprovados, o mecanismo de ação ainda não foi elucidado. Parece que o mecanismo de ação das antocianinas é semelhante ao das saponinas, formando micelas com ácidos biliares e sendo incapazes de serem absorvidas no intestino.

Os carotenóides possuem mais de 600 variantes estruturais e são encontrados em bactérias, algas, fungos e plantas superiores, em alguns crustáceos e em plumagem de aves. Os carotenóides possuem ligações duplas conjugadas em suas estruturas, atuam como antioxidantes (FONTANA et al., 2000). Diversos trabalhos foram conduzidos para verificar os efeitos hipocolesterolêmico dos carotenóides em animais e humanos. Os principais carotenóides utilizados em pesquisas são os oriundos do urucum (bixina e norbixina) e o carmim.

A bixina tem sido utilizada para controlar a hiperlipidemia e a aterosclerose, pois, possui atividade ativadora sobre a enzima lípase lipoprotéica. Esse mecanismo pode ser explicado pela formação de quelatos entre a enzima e a bixina, que induzem a mudança conformacional da enzima, modificando seu centro ativo. Porém, no organismo animal atua como antioxidante, a bixina protege o endotélio do animal à oxidação da LDL (LIMA et al., 2001). Ao alimentar codornas japonesas machos com rações contendo colorífico do extrato de urucum Oliveira et al. (2008), não constatou redução nos níveis de triacilgliceróis e lipídios totais no sangue e na carne das aves.

O carmim é um pigmento vermelho cujo principal cromóforo é o ácido carminico obtido pelo extrato aquoso ou seco de fêmeas de Dactylopius coccus, mais conhecido como cochonilha. Apresenta a propriedade de fixar-se em proteínas, o que torna útil na coloração de produtos à base de leite, como iogurtes e sorvetes bem como em revestimentos de produtos farmacêuticos e não apresenta efeitos toxicológicos, mutagênicos e carcinogênicos (LAURO, 1995). 


\section{ACIA

As saponinas são compostos naturais do grupo dos terpenos sintetizados a partir do acetilCoA ou intermediários glicolíticos. São caracterizados pelo ponto de vista estrutural por apresentar ligações glicosídicas e éster entre uma genina pouco polar e resíduos glicídicos. Pela atividade se caracterizam por formar espuma em soluções aquosas e por hemolisar os glóbulos vermelhos. Sob hidrólise produzem esteróides, açúcares e triterpenóides e tem capacidade de formar espuma em solução aquosa. A capacidade detergente das saponinas deve-se a presença de elementos triterpenos (C30 - lipossolúvel) e um açúcar (hidrossolúvel) numa única molécula. Podem ser encontradas em diversas plantas (leguminosas, chás, espinafre, beterraba, alho e berinjela) e o teor varia em função da resistência da planta à herbivoria, uma vez que a saponina confere sabor amargo à planta (ANNONGU et al., 1996). São classificadas em: esteróides e triterpenóides e ambas podem formar complexos insolúveis com o colesterol. Apesar das saponinas esteróides formarem complexos mais estáveis com o colesterol, possuem baixa capacidade em relação às saponinas triterpenóides (LÁSZTITY et al., 1998).

A formação dos complexos saponinas/ triterpenóides/ colesterol formam micelas, que por interação hidrofóbica entre as moléculas de saponina e ácidos biliares impedem a absorção das micelas contendo colesterol exógeno no intestino. Foi observado inibição da difusão passiva do ácido cólico pelas saponinas da erva-mate através da diálise em membrana, pela formação de micelas entre o ácido cólico e as saponinas (FERREIRA et al.,1995).

As saponinas das raízes de ginseng vermelho reduzem a atividade da enzima acil-CoA colesterol transferase in vitro. Há relatos na redução na concentração da enzima HMG-CoA redutase e no colesterol plasmático de galinhas poedeiras alimentadas com ração contendo 0,25\% de raiz de ginseng (QURESHI et al., (1983).

\subsection{Carvão vegetal}

Carvão vegetal é definido como resíduo carbonizado da madeira, celulose ou casca do coco ou material de origem vegetal isenta de oxigênio. Possui uma ótima ação adsorvente de micotoxinas, drogas e substâncias lipossolúveis a nível intestinal sem ser absorvido. É utilizado com a finalidade de reduzir a gordura total na carcaça e a obesidade em frangos e a redução do colesterol do ovo de galinhas.

Kutlu et al., (2001) observaram aumento da excreção de lipídios nas fezes de pintainhos ( 1 a 21 dias), com o aumento dos níveis de carvão na ração, porém sem observar diminuição na gordura corporal. Os autores explicam que a possível causa para isso é a síntese deficiente de bile pelos pintainhos, dificultando a digestão lipídica, sendo a gordura proveniente da dieta, adsorvida pelo carvão. Souza et al., (2001) verificaram a redução em 22\% do colesterol do ovo de poedeiras e $34 \%$ da carne de frangos em rações com 3\% de carvão vegetal. Além disso reduziu a umidade nas fezes das aves, devido a ação adstringente do carvão.

Por outro lado, Oba et al. (2005) concluíram que as cinzas de carvão vegetal apesar de melhorar a qualidade da casca do ovo, não reduz a concentração de colesterol na gema. Analogamente, Fanchiotti et al. (2010) corroboram ao concluírem que não houve redução significativa na concentração do colesterol plasmático e no ovo de poedeiras alimentadas com rações contendo óleos vegetais associados ao carvão vegetal e a vitamina E.

\subsection{Micronutrientes}

Muitos micronutrientes têm sido objeto de estudo sobre seus possíveis efeitos no metabolismo do colesterol na poedeira. Ambos, Dua et al. (1967) e Weiss et al. (1967), não 
encontraram efeito da suplementação com vitamina A sobre o nível de colesterol na gema do ovo. Semelhantemente, Singh (1972) reportaram não terem encontrado influência do nível de niacina sobre o colesterol do ovo.

Helwig et al. (1978) demonstraram que diferentes relações de zinco e cobre na dieta de poedeiras não influenciaram no teor de colesterol plasmático e no ovo. Resultado semelhante foi encontrado por Labate e Dam (1980) ao injetarem ácido hidroximetilglutárico (HMG) em fêmeas de codornas japonesas, assim como a suplementação com vanádio não causou qualquer efeito significativo sobre a produção de ovos e no nível de colesterol no ovo.

Estudos com cobre foram conduzidos por Ankari et al. (1998) e Pesti e Bakalli (1998), que observaram redução significativa no colesterol total no sangue e no ovo de poedeiras suplementadas com $250 \mathrm{mg} \mathrm{Cu} / \mathrm{kg}$ de dieta. Kim et al. 1992 também concluíram que uma dieta deficiente em cobre causa hipercolesterolemia e aumenta a atividade da 3-hidroxi-3-metilglutaril coenzima A redutase no fígado, enzima que catalisa a formação do mevalonato, um precursor do colesterol. O inverso também ocorre, ou seja, com o aumento da ingestão cobre pela ave, ocorre uma redução na atividade da enzima e, consequentemente uma menor síntese de colesterol no fígado. Entretanto, a utilização de níveis acima de $1000 \mathrm{mg}$ de cobre/kg inibe a produção de ovos através da redução do hormônio 17- $\beta$-estradiol (PEARCE et al., 1983).

Em relação ao crômio, Oba et al. (2005) que o mineral não melhora a eficiência metabólica na redução do colesterol e dos lipídios, tanto no sangue, como no ovo de galinhas poedeiras. Esses resultados contrariam os achados de Uyanik et al. (2002), que ao fornecerem crômio na dieta de galinhas poedeiras observaram reduções significativas no colesterol total e triglicérides no sangue e colesterol total no ovo.

Com o desenvolvimento da indústria de microingredientes, os probióticos foram objeto de extensos estudos nas mais diversas aplicações, dentre elas sobre a influência na deposição de colesterol na gema do ovo. Alguns desses estudos indicam que a adição de probiótico à ração reduz significativamente o colesterol total e triglicéridios no sangue, porém, não afeta o colesterol e lipídios totais nos ovos (PANDA et al., 2003; MAHDAVI et al., 2005; OBA et al., 2005).

O mecanismo de redução pode estar relacionado com a assimilação do colesterol pelos microrganismos presentes no probiótico ou sua degradação para ácidos biliares, seguido pela desconjugação, impedindo uma nova síntese. A redução pode ser atribuída à diminuição da absorção ou síntese de colesterol no trato gastrointestinal. Todavia, ainda não há consenso sobre esses mecanismos (OBA et al., 2005).

\section{Considerações finais}

Os resultados descritos na literatura apresentados nesta revisão, compõe um acervo imprescindível para o desenvolvimento de estratégias nutricionais a fim de reduzir a concentração do colesterol na gema do ovo. Como discutido nas diversas abordagens os resultados de fato não permitem asseverar para uma estratégia específica, uma vez que estão embutidas nos protocolos, diferentes metodologias para quantificação do colesterol, formulação e perfil do biomodelo avaliado, como linhagem, idade e peso das aves.

Desta maneira, há de desconsiderar a cronologia das referências, pois, os resultados expressivos e as discussões apresentadas são determinantes para replicações de experimentos com metodologias padronizadas e atualizadas às necessidades da avicultura contemporânea. De fato, estudos complementares são indicados para elucidar os mecanismos ainda não compreendidos.

\section{Referências}


ANKARI, A.A.L, NAJIB, H, HOZAB, A.A.L. Yolk and serum cholesterol and production traits, as affected by incorporating a supraoptimal amount of copper in the diet of the leghorn hen. British Poultry Science, v. 39, p. 393-397, 1998.

ANNONGU, A.A., ter MEULEN, U., ATTEH, J.O., CHINNAH, T. Biochemical and histological alterations in the liver of the broiler after ingestion of vegetable saponins and effects of dietary supplementation with adsorbents or methyl donor. Archive fur Geflugelkunde, v.60 (6), p.267$272,1996$.

AUSTIC, R.E.; Nutritional influences on positive product characteristics eggs. Poultry Adviser, v.27, n.2., p.41-47, 1994.

BARTOV, I.; BORNSTEIN, S.; BUDOWSKI, P. Variability of cholesterol concentration in plasma and egg yolks of hens and evaluation of the effect of some dietary oils. Poultry Science, v.50, p.1357-1364, 1971.

BAUCELLS, M.D.; CRESPO, N.; BARROETA, A.C.; ET AL. Incorporation of different polyunsaturated fatty acids eggs. Poultry Science, v.79, p.51-59, 2000.

BEYER, R.S.; JENSEN, L.S. Tissue and eggs cholesterol concentrations of alying hens fed highprotein barley flour, $\alpha$-tocotrienol and cholesterol. Poultry Science, v.72, p.1339-1348, 1993.

BITMAN, J.; WOOD, D.L. Cholesterol and cholesteryl esters of eggs from avian species. Poultry Science, v.59, p.2014-2023, 1980.

BROUILLARD, R. The in vivo expression of anthocyanin colour in plants. Phytochemistry, v.22, n.6, p.311-23, 1983.

CLARENBURG, R.; KIM CHUNG, I.A.; WAKEFIELD, L.M. Reducing the egg cholesterol level by including emulsified sitosterol in standard chicken diet. Journal of Nutrition, v.101, p.289298, 1971.

COSTA, F.G.P.; SOUZA, J.G.; SILVA, J.H.V. et al. Influência do óleo de linhaça sobre o desempenho e a qualidade dos ovos de poedeiras semipesadas. Revista Brasileira de Zootecnia, v.37, n.5, p.861-868, 2008.

DELGADO-VARGAS, F. JIMÉNEZ, A.R., PAREDES-LÓPEZ, O. Natural pigments: carotenóids, anthocyanins, and betalains - characterístics, biosyntesis, processing and stability. Critical Reviews in Food Science and Nutrition, v.40, n.3, p.173-289. 2000.

DUA, P.N.; DILWORTH, B.C.; DAY, E.J.; HILL, J.E. Effect of dietary vitamin A and cholesterol on cholesterol and carotenoid content of plasma and egg yolk. Poultry Science, v.46, p.530-531, 1967.

ERLUND, I. Review of the flavonoids quercetin, hesperetin, and naringenin. Dietary sources, bioactivities, bioavailability and epidemiology. Nutrition Research. v.24, p.851-874. 2004. 
FANCHIOTTI, F.E.; MORAES, H.H.K.; BARBOSA, A.A.; ALBINO, L.F.T.; CECON, P.R.; MOURA, A.M.A. Avaliação de óleos, carvão vegetal e vitamina E no desempenho e nas concentrações lipídicas do sangue e dos ovos de poedeiras. Revista Brasileira Zootecnia, v.39, n.12, p.2676-2682, 2010.

FERREIRA, F., VASQUEZ, A., GUNTNER, C., MOYNA, P. Inhibition of the passive diffusion of cholic acid by the Ilex paraguariensis (A. St. Hill). saponins. Phytotherapy Research, v.11, n.1, p.79-81. 1995.

FISHER, H.; LEVEILLE, G.A. Observations on the cholesterol, linoleic and linolenic acid content of eggs as influenced by dietary fats. Journal of Nutrition, v.63, p.119-129, 1957.

FONTANA, J.D., MENDES, S.V., PERSIKE, D.S. et al. Carotenóides. Biotecnologia Ciência e Desenvolvimento,. v.3, p.40-45. 2000.

GRIMINGER, P. Lipid metabolism. In: Sturkie, P.D. (ed). Avian Physiology. 4 ed., New York: Springer-Verlag, p.345-358, 1986.

GUIMARÃES, P.R., GALVÃO, A.M.P., BATISTA, C.M., et al. Eggplant (Solanum mellongena) infusion has a modest and transitory effect on hypercholesterolemic subjects. Brazilian Journal of Medical and Biological Research, v.33, n.9, p.1027-1036. 1996.

HARGIS, P.S.; VAN ELSWYK, M.E. HARGIS, B.M. Dietary modification of yolk lipid with Menhaden oil. Poultry Science, v. 70, n.4, p.874-883, 1991.

HELWIG, I.R.; MULNIX, E.J.; REGENSTEIN, J.M. Effects of varied zinc/copper rations on egg and plasma cholesterol level in White Leghorn hens. Journal of Food Science, v.43, p.606-669, 1978.

HIRATA, A.; NISHINO, M.; KIMURA, T.; OHTAKE, Y. Effects of dietary fats for laying hensin the fatty acid compositions and cholesterol contents of liver, abdominal adipose tissue, plasma and egg yolk lipids. Journal of the Japanese Society of Food Science Technology, v.33, p.631-639, 1986.

HODZIC, A.; HAMAMDZIC, M.; GAGIC, A. et al. Egg yolk lipid modifications by fat supplemented diets of laying hens. Acta Veterinaria, v.55, n.1, p.41-51, 2005.

IGARASHI, K., KIMURA, Y. TAKENAKA, A. Preventive effects of dietary cabbage acylated anthocyanins on paraquat-induced oxidative stress in rats. Bioscience Biotechnology an Biochemistry, v.64, n.8, p.1600-1607. 2000.

JACKSON, R.L.; LIN, H.Y.; MAO, J.T.S.; ET AL. Estrogen induction of plasma vitellogenin in the cocketel: studies with a phosvitin antibody. Endocrinology, v.101, p.849-857, 1977.

KIM, S.; CHAO, P.Y.; ALLEN, G.D.A. Inhibition of elevated hepatic glutathione abolishes copper deficieny cholesterolemia. FASEB Journal, v.6, p.2467-2471, 1992. 
KLASING, K.C. Lipids. In: Comparative avian nutrition. CAB international, Oxon, UK. p.171200. 1998.

KOVACS, G.; SCHIMIT, J.; HUSVETH, F.; DUBLECZ, K.; WAGNER, L.; FARKAS, Z.E. Effect od feed composition on cholesterol content of the table egg. Acta Alimentaria, v.29, n. 1, p. 25-41, 2000.

KUDCHODKAR, B.J.; HORLICK, L.; O’NEIL, J.B. Absorption of dietary $\beta$-sitosterol in laying hens and its incorporation into egg. Journal of Nutrition, v.106, p.1629-1636, 1976.

KUTLU, H.R, UNSAL, I., GORGULU, M. Effects of providing dietary wood (oak) charcoal to broiler chicks and laying hens. Animal Feed Science and Technology. v.90, p.213-226. 2001.

LABATE, M.E.; DAM, R. Effect of 3-hydroxy-3-methylglutaric acido n cholesterol metabolism in female Japanese quail. Poultry Science, v.59, p.383-389, 1980.

LAURO, G.J. Handbook of natural color. Placentia: La Monde. p.7-27. 1995.

LÁSZTITY, R. HIDVÉGI, M. BATA, A. Saponins in food. Food Reviews International, v.14, n.4, p.371-390. 1998.

LIMA, L.R.P., OLIVEIRA, T.T., NAGEM, T.J., PINTO, A.S. et al. Bixina, norbixina e quercetina e seus efeitos no metabolismo lipídico de coelhos. Brazilian Journal Research of Animal Science, v.38, n.4, p.196-200. 2001.

MAHDAVI, A.H, RAHMANI, H.R, POURREZA, J. Effect of probiotic supplements on egg quality and laying hen's performance. International Journal of Poultry Science, v.4, p.488-492, 2005.

MAYNARD, L.A.; LOOSLI, J.K.; HINTZ, H.F.; WARNER, R.G. Nutrição Animal. Tradução de Antônio B. Neiva Figueredo Filho. Rio de Janeiro: Livraria Freitas Bastos S.A., 726p. 1984.

MENDONÇA JR, C.X.; MARTINS, A.P.; MORI, A.A.V.; SILVA, E.B.; MORI, C.S. Efeito da adição de óleo de peixe à dieta sobre o desempenho eníveis de lipídios plasmáticos e de colesterol no ovo de galinhas poedeiras. Brazilian Journal of Veterinary Research and Animal Science, v.37, n.1, 2000.

MOGHADASIAN, M.H. Pharmacological properties of plant sterols in vivo and in vitro observations. Life Sciences, v.67, p.605-615, 2000.

MORETTO, E., FETT, R. Tecnologia de óleos e gorduras vegetais na indústria de alimentos. São Paulo: ed. Varela, 150p. 1998.

MORI, A.V.; MENDONÇA JR., C.X.; SANTOS, C.O.F. Effect of dietary lipid - lowering drugs upon plasma lipids and egg yolk cholesterol levels of laying hens. Journal of Agricultural and Food Chemistry, v.47, n.11, p.4731-4735, 1999. 
MURAMATSU, K., FUKUYO, M., HARA, Y. Effect of green tea catechins on plasma cholesterol level in cholesterol-fed rats. Journal Nutrition Science Vitaminol, v.32, p.613-622. 1986.

MURATA, L.S.; ARIKI, J.; MACHADO, C.R. et al. Effect of oils sources on blood lipid parameters of commercial laying hens. Brazilian Journal of Poultry Science, v.5, n.3, p.203-206, 2003.

NABER, E.C. Nutrient and drug effects on cholesterol metabolism in laying hen. Federation Proc., v.42, p.2486-2493, 1983.

NIMPF, J.; SCHNEIDER, W.J. Receptor-mediated lipoprotein transport in laying hens. Journal of Nutrition, v.121, n.9, p.1471-1474, 1991.

NOBLE, R.C.; SPEAK, B.K.; MCARTNEY, R. Yolk lipids and their fatty acids in the wild and captive ostrich (Strutio camelus). Comparative Biochemistry and Physiology B - Biochemistry and Molecular Biology, v.113, p.753-756, 1996.

OBA, A.; SOUZA, P.A.; SOUZA, H.B.A., NORKUS, E.A., CERQUEIRA, A.A. Características produtivas e níveis de colesterol total no sangue e nos ovos de poedeiras comerciais alimentadas com dietas suplementadas com cinza vegetal, cobre, crômio e probiótico. Revista Portuguesa de Ciências Veterinárias, v.100, n.555-556, p.205-210, 2005.

OLIVEIRA, T.T., NAGEM, T.J., SILVA, M.C., MIRANDA, L.C.G., TEIXEIRA, M.A. Ação antioxidante de flavonóides modificados. Pesquisa Agropecuária Brasileira, v.34, n.5, p.879883. 1999.

OLIVEIRA, T.T., PEREIRA, W.L., NAGEM, T.J., PINTO, A.S., SANTOS, C.A. Efeito regulatório de flavonóides e de carmim nos níveis de lipídeos em ratos Wistar. Arquivo Brasileiro de Medicina Veterinária e Zootecnia. v.54, n.1, p.1-6. 2002.

PANDA, A.K, REDDY, M.R, RAO, S.V.R, PRAHARAJ, N.K. Production performance, serum/yolk cholesterol and immune competence of White Leghorn Layers as influenced by dietary supplementation with probiotic. Tropical Animal Health and Production, v.35, p.85-94, 2003.

PEARCE, J, JACKSON, N, STEVENSON, M.H. The effects of dietary intake and of dietary concentration of cooper sulphate on the laying domestic fowl: effects on some aspects of lipid, carbohidrate and amino acid metabolism. British Poultry Science, v.24, n.337-348, p.1983.

PETERSON, J., DWYER, J. Flavonoids: Dietary occurrence and biochemical activity. Nutrition Research, v.18, n.12, p.1995-2018. 1998.

PESTI, G.M, BAKALLI, R.I. Studies on the effect of feeding cupric sulfate pentahydrate to laying hens on egg cholesterol content. Poultry Science, v.77, p.1540-1545, 1998.

PIIRONEN, V.; LINDSAY, D.G.; MIETTINEN, T.A.; ET AL. Plant sterols: biosynthesis, biological function and their importance to human nutrition. Journal of the Science of Food and Agriculture, v.80, p.936-966, 2000. 
QURESHI, A.A.; ABUIRMEILEH, N.; DIN, Z.Z.; ET AL. Suppression of cholesterogenesis and reduction of LDL cholesterol by dietary gisensg and fractions in chicken liver. Atherosclerosis, v.48, p.81-94, 1983.

SARNI-MANCHADO, P. S.; FULCRAND, H.; SOUQUET, J.M.; CHEYNIER, V.; MOUTOUNET, M. Stability and color of unreported wine anthocyanin-derived pigments. Journal of Food Science, v.61, n.5, p.938-941, 1996.

SHAFEY, TM. The role of lipoproteins in lipid metabolism of chickens. Journal of King Saud University-Agricultural Sciences, v.13, n.1, p.91-113, 2001.

SHAFEY, TM. Effects of dietary retinol and sunflower oil on the performance and on the lipoproteins, lipids, cholesterol and retinol concentrations of plasma and egg of laying hens. Arabian Gulf Journal Scientific Research, v.16, n.2, p.331-345, 1998.

SHAFEY, TM.; DINGLE, J.G.; McDONALD, M.W. The relationships between egg yolk cholesterol, egg production and age of the hen in three Australian layer strains. Journal of King Saud University-Agricultural Sciences, v.10, n.1, p.33-41, 1998.

SIM, J.S.; BRAGG, D.B. Effect of dietary factors on serum and egg yolk cholesterol levels of laying hens. Poultry Science, v.56, p.1616-1621, 1977.

SIM, J.S.; KITTS, W.D.; BRAGG, D.B. Influence of dietary oil, cholesterol and soysterols on the fecal neutral and acidic steroid excretion in laying hens. Poultry Science, v.59, p.325-327, 1980.

SINGH, R.A. Effect of D-thyroxine and nicotinic acid on cholesterol metabolism in laying hen. Indian J. Animal Science, v.42, p.433-435, 1972.

SOUZA, P.A., SOUZA, H.B.A., OBA, A., GARDINE, C.H.C., KODAWARA, L.M. Levels of cholesterol in the blood, meat and egg of commercial laying hens submitted to diets containing vegetable charcoal. Pesquisa Fapesp. São Paulo, n.61, p.60-61. 2001.

SUTTON, C.D.; MUIR, W.M.; MITCHELL, G.E. Cholesterol metabolism in the laying hen as influencied by dietary cholesterol, caloric intake and genotype. Poultry Science, v.63, n.5, p.972980, 1984.

SUTTON, C.D.; MUIR, W.M.; BEGIN, J.J. Effect of fiber on cholesterol metabolism in the Coturnix quail. Poultry Science, v.60, p.812-817, 1981.

TAIZ, L., ZEIGER, E. Surface protection and secondary defense compounds. Plant Physiology. 2 ed. Massachusetts: Sinauer Associates Inc., chap. 13. p.347-376. 1998.

UYANIK, F, KAYA, S, KOLSUZ, A.H, EREN, M, SAHIN, N. The effect of chromium supplementation on egg production, egg quality and some serum parameters in laying hens. Turk Veterinarlik ve Hayvancilik Dergisi, v.26, p.379-387, 2002. 
VARGAS, R.E.; NABER, E.C. Relationship between dietary fiber and nutrient density and its effect on energy balance, egg yolk cholesterol and hen performance. Journal of Nutrition, v.114 n.4, p.645-652, 1984.

VILCHEZ, C.; TOUCHBURN, S.P.; CHAVEZ, E.R.; CHAN, C.W. Effect of feeding palmitic, oleic and linoleic acids to Japanese quail hens (Coturnix coturnix japonica). 1. Reproductive performance and tissue fatty acids. Poultry Science, v.70, p.2484-2493, 1991.

WALZEN, R.L. Lipoproteins and laying hen: form follows function. Poultry and Avian Biology Reviews, v.7, p.31-64, 1996.

WEISS, J.F.; JOHNSON, R.M.; NABBER, E.C. Effect of some dietary factors and drugs on cholesterol concentration in the egg and plasma of the hen. Journal of Nutrition, v.91, p.119-128, 1967.

WESTER, I. Cholesterol-lowring effect of plant sterols. European Journal of Lipids Science and Technology, v.102, n.1, p.37-44, 2000. 